\title{
El proyecto fracasado del último obispado del norte de la Nueva España. Hacia la creación de la diócesis de Nuevo México/
}

\author{
The failed project of the last bishopric \\ of the north of the New Spain. Towards the creation \\ of the diocese of New Mexico
}

Jesús Paniagua Pérez

Universidad de León, España

Los habitantes de nuevo México tuvieron desde la época de Oñate el deseo de disponer de un obispado, que se acrecentó en la medida que lo hacían los sentimientos autonomistas. Los motivos variaban. Los franciscanos por evitar el control del obispo de Durango. Los habitantes de Nuevo México, porque veían una forma de promoción espiritual y material, así como el desarrollo de centros de formación. El proyecto estuvo a punto de realizarse en las Cortes de Cádiz, tras la intervención del diputado por Nuevo México Pedro Baptista Pino, en colaboración con el periodista Juan López Cancelada. El regreso de Fernando VII daría al traste con aquel proyecto de diócesis, que solo se crearía tras la anexión a los Estados Unidos.

Palabras Clave: Obispado; Nuevo México; Proceso de fundación; Siglos XVII al XIX.

The inhabitants of New Mexico had from the epoch of Oñate the desire to have an bishopric, that increased in the measure that autonomists were increasing the desires. The motives were varied. The Franciscans to avoid the control of the bishop of Durango; the inhabitants because they saw in it a form of spiritual and material promotion, as well as the development of centers of formation. The project almost was realized in the Cortes de Cádiz. after the intervention of the deputy for New Mexico, Pedro Baptista Pino, in collaboration with the journalist Juan López Cancelada. The return of Fernando VII would finish with the project. It would be necessary to wait to the annexation to the United States in order that the new diocese was created.

KeYwORDS: Bishopric; New Mexico; Process of foundation; XVIIth to XIXth century. 
Los territorios de Nuevo México habían sido adscritos a la diócesis de Durango, desde que esta fue creada por bula de Pablo V de 11 de octubre de $1620 .{ }^{1}$ Se integrarían además los de Nueva Vizcaya, Sonora, Sinaloa, Chihuahua, las Californias y parte de Coahuila y Zacatecas, incluidos también todos aquellos «que se extendían hasta la apachería». ${ }^{2}$ Por tanto, fue aquella una diócesis de frontera que ocupó gran parte del inmenso y mal delimitado espacio del norte de la Nueva España.

La consecuencia fue que los prelados se sintieron muchas veces impotentes para controlar un espacio tan amplio, al menos más allá de lo que podían hacer los misioneros - que en el caso de Nuevo México fueron exclusivamente los franciscanos-, con su custodia de la Conversión de San Pablo, dependiente de la provincia del Santo Evangelio de México, desde su fundación en 1616. No es de extrañar, por tanto, que incluso en vísperas de la independencia se insistiera en las Cortes de Cádiz en la necesidad de una diócesis, como también lo plantearon otros lugares, algunos menos necesitados y problemáticos que Nuevo México, cuyos territorios estaban habitados por un mosaico de pueblos indios.

Las Cortes de Cádiz, que fueron el eco de muchas de las pretensiones de los americanos, también sirvieron para intentar que se atendieran viejas aspiraciones en lo eclesiástico. Un obispado no solo suponía el control en lo religioso de una demarcación territorial, sino un aumento de autonomía, una cierta reactivación económica, al menos de la capital diocesana, y un avance en lo educativo; asunto este último al que eran muy sensibles las autoridades y algunos ciudadanos tras décadas de influencia de la Ilustración.

Como consecuencia de lo anterior Culiacan solicitaba su diócesis en 1811. Mariano Mendiola reclamaba en una larga exposición en las Cortes varías cosas para Querétaro, entre ellas, que se pusiese en marcha el obispado, que se ya se había solicitado en $1805,{ }^{3}$ pero que no se llegaría a crear hasta 1864 por la bula Deo optimo maximo. El venezolano Rus llevaba en mente la creación de un obispado en Maracaibo, separado de Mérida, lo que se conseguiría por traslado de la silla episcopal en $1813 .{ }^{4}$ Florencio Castillo hacía su solicitud para Costa Rica el 10 de mayo del mismo año. En el caso de Puno, su diputado no pidió una nueva diócesis, como se le recomendaba

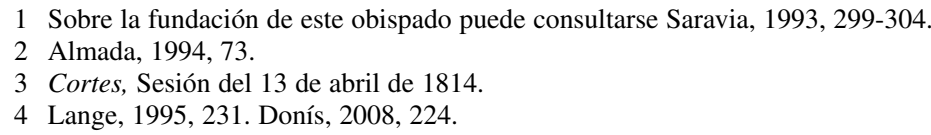


en sus instrucciones, sino que optó por solicitar la división de los curatos. ${ }^{5}$ Incluso, como reflejo del autonomismo del Norte de la Nueva España, se pretendía elevar Guadalajara a la categoría de archidiócesis por voz del diputado José Simeón de Uría, asunto en el que seguirían insistiendo al monarca en años posteriores, tanto el cabildo secular como el eclesiástico. ${ }^{6}$

Toda esta problemática con los obispados no hay que desvincularla del pretendido autonomismo de los territorios del norte, cuya máxima expresión sería la solicitud en 1814 del diputado por Nueva Galicia, José Sánchez Resa, para que Guadalajara se convirtiese en la capital de un nuevo virreinato septentrional o al menos de una capitanía general. ${ }^{7}$ Igualmente, Pedro Baptista Pino, como representante por Nuevo México en las Cortes, también había propuesto la creación de una Real Audiencia con sede en Chihuahua, ${ }^{8}$ idea que reavivaba la mantenida en su día por Gálvez y Croix, ya que este último había pensado en 1778 en el establecimiento de una Audiencia en Arizpe, tema que quedó en punto muerto con la llegada al trono de Carlos IV, volviéndose a resucitar en Cádiz por los diputados Pino (Nuevo México), Guereña (Durango) y Ramos Arizpe (Coahuila). ${ }^{9}$ Es decir, se apreciaba en el norte todo un deseo de reorganización para liberarse en todos los sentidos de la administración civil, militar y eclesiástica del resto de la Nueva España, ${ }^{10}$ convirtiendo a Guadalajara en la nueva capital y potenciando otras ciudades y villas como Chihuahua, Durango, Culiacan, Arizpe, Santa Fe, etc.

\section{Los precedentes del obispado de Nuevo México. La lucha por el control entre franciscanos y prelados}

Aunque el planteamiento más serio sobre el asunto no se produciría hasta las Cortes de Cádiz, conviene recordar que los deseos de la creación de un obispado en Nuevo México son casi tan antiguos como su definitiva conquista por Juan de Oñate. ${ }^{11}$ Este había intentado que aquellos territorios, de delimitación indefinida, fueran sede de una diócesis o, en su defecto, de

5 Rieu-Millan, 1990, 260-261.

6 López, 1964, 26.

7 Zárate, 1988, 371.

8 Pino y López, 2007, 180.

9 Cutter, 277-292.

10 Véanse abundantes ejemplos en Navarro, 1964.

11 Sobre algunos de los precedentes puede verse Simons, 1998, 212-213. 
una abadía o un vicariato. Es muy probable que el conquistador quisiese evitar la injerencia del obispo de Guadalajara, que reclamaba aquella jurisdicción desde 1596. Como Oñate era consciente de que las rentas producidas en aquellos territorios no darían para crear una nueva diócesis, proponía, como hemos mencionado, otras posibilidades que permitieran cierta autonomía eclesiástica. Así, se mencionaba la posibilidad de una abadía, solución que se había materializado o se había intentado en otros lugares de las Indias, amén de la primigenia de Jamaica. Así, Santa Marta adquirió ese rango cuando su obispado fue trasladado a Santafé de Bogotá, en 1534, hasta 1577, en que se erigió de nuevo en obispado. ${ }^{12}$ En Florida se pensó en esa solución en la primera mitad del siglo XVII ${ }^{13}$ y se seguían insistiendo en ella en 1655, alegando siempre la imposibilidad de control del obispo de La Habana, por lo que acabaría fundándose la abadía de San Agustín de Florida. ${ }^{14}$ Hacia 1631 también se había erigido la abadía de Santo Tomé de Guayana. ${ }^{15}$ En Nueva España existía además la abadía de Pánuco y Tampico, a la que correspondían los diezmos de la Huaxteca. Sin embargo, en Nuevo México no triunfó la proposición de Oñate al rey, en 1602, que el conquistador ya había madurado con anterioridad. ${ }^{16}$

Los preámbulos del obispado neomexicano estarían íntimamente ligados a la labor misional de los franciscanos, que en lo religioso defendieron el control de aquel territorio y evitaron por todos los medios cualquier intento de secularización de sus doctrinas, que lograron mantener hasta el periodo independentista por encima de todos los proyectos que hubo de secularización. ${ }^{17}$ Esto supuso continuos enfrentamientos con los prelados de Durango y propuestas de soluciones, entre las que ya estaba la erección de una nueva diócesis. Ya el primer obispo durangués, fray Gonzalo de Hermosillo, tuvo que soportar que los franciscanos evitasen su visita a Nuevo México. ${ }^{18}$ Se abría así una etapa de pretensiones autonomistas reli-

12 Archivo General de Indias (AGI), Patronato, 1, N. 29. «Copia del licenciado Fernando Paniagua por la que queda Santa Marta constituida en abadía». Madrid, 24 de julio de 1680.

13 AGI, Indiferente, 455, L. A26, 275v-283, «Real cédula sobre la conveniencia de fundar una abadía en Florida», Madrid, 24 de marzo de 1646.

14 Cárdenas, 1722, 219, 245.

15 AGI, Quito 88, N. 39, «El tesorero de la catedral de Popayán solicita se le presente a la abadía mandada erigir en Santo Tomé de la Guayana», Popayán, 21 de febrero de 1631.

16 AGI, México, 121 y 124, «Cartas de Juan de Oñate al rey solicitando una jurisdicción eclesiástica para Nuevo México», 1602.

17 Sobre la historia eclesiástica de Nuevo México en el siglo XVII puede verse Scholes 1936 y 1937.

18 Cramaussel, 2000, 72. 
giosas en aquella provincia, que permanecieron vivas hasta la independencia, con un especial empuje durante las Cortes de Cádiz; aunque para entonces, como veremos, los intereses se habían hecho más complejos. De momento, se trataba de evitar intromisiones en territorios de la custodia franciscana de la Conversión de San Pablo, alegando para ello los beneficios concedidos a los seráficos por papas como Adriano VI y Sixto V. Lo cierto es que la solución que vieron los frailes fue la de erigir una diócesis, cuyos prelados saliesen de su misma Orden, lo que les liberaba de las intromisiones de Durango. Así, la Corona llegó a pedir información al virrey marqués de Cerralbo (1624-1635), que en una misiva mostraba su conformidad y consideraba que para regir aquella diócesis se podía pensar en el custodio que lo fuese de la provincia neomexicana. ${ }^{19}$

De esa época de Cerralbo datan las noticias que aparecieron en 1630, al publicarse en Madrid el memorial de fray Alonso de Benavides, donde se solicitaba ya la erección de una diócesis neomexicana, lo que contó con el visto bueno del fiscal del Consejo de Indias, Juan de Solórzano ${ }^{20}$ aunque no llegó a concretarse. El memorial era toda una exaltación de la labor de los hijos de San Francisco, en que se aprecia el olvido consciente de la dependencia del obispado de Durango ${ }^{21}$ y el interés del autor por ser el primer prelado.22

La época del virrey marqués de Cadereyta (1635-1640) fue de especial actividad en aquellas pretensiones de crear una diócesis neomexicana vinculada a la Orden franciscana. El propio monarca había encargado al mandatario, en 1637, que manifestase si era oportuna la escisión de dos nuevos obispados en Sonora y Nuevo México. Al año siguiente, el 26 de septiembre, el monarca también solicitó un informe al comisario general de los franciscanos en Nueva España, ${ }^{23}$ que había pasado por entonces a ocupar su cargo. ${ }^{24}$ Se pusieron entonces de manifiesto las dos soluciones posi-

19 AGI, México 31, N. 2, «El virrey sobre el obispado de Nuevo México», México, 20 de marzo de 1632.

20 Hodge, 1945, 11.

21 Benavides, 1630. Natural de la isla de San Miguel, en las Azores, se dice que fue nombrado obispo auxiliar de Goa, aunque no se tienen otras noticias, y se ha llegado a suponer que murió en 1635 en el viaje a la India. Se menciona en los Diálogos, 1811, 59. Es cierto que en esos años en que se le nombraba obispo auxiliar de Goa existía un grave problema, pues pretendía ser nombrado como tal el jesuita P. Juan de Rocha, contra de la voluntad del propio Felipe IV y de su Instituto e incluso protagonizó grandes enfrentamientos con el Cabildo catedralicio. Estos asuntos pueden verse en el volumen XII de la obra de Beccari y en Santos, 2000, 60-63.

22 Kessell, 1987, 150.

23 Vázquez, 2004, 88.

24 AGI, Contratación, 5420, N. 25 y Pasajeros, L. 11, E. 3472. 
bles que beneficiarían a los seráficos. Por un lado, el Comisario informó que, puesto que no había clérigos seculares en Nuevo México, daba por hecho que aquel territorio no estaba sujeto al diocesano y que ni siquiera era conveniente crear un obispado, debido a la pobreza del territorio, siendo los custodios franciscanos suficientes para la atención espiritual. ${ }^{25}$ Por otro lado, el virrey, también favorable en aquel asunto a los frailes, apoyaba la erección de una diócesis, pero con prelados de la Orden, como lo manifestó en 1639;:26 es más, para ocupar la mitra proponía a fray Miguel de la Cruz, que había sido provincial y predicador en Sonora; o a fray Francisco Rodríguez. ${ }^{27}$ Igualmente en tiempos de este virrey, y siendo el segundo prelado de Durango Alonso Franco y de Luna, se resucitó la vieja solución de Oñate de convertir Nuevo México en una abadía, que podría mantenerse con los 2.000 pesos obtenidos en diezmos. ${ }^{28}$

Pero la relación de Cadereyta con los franciscanos se tambaleó a causa del nombramiento como gobernador de Nuevo México de Luis de Rosas (1637), cuya relación con los misioneros fue pésima y desembocó en el famoso levantamiento de 1641, alentado por los frailes, que le costó la vida a Rosas y de lo que le tocó informar e investigar como virrey interino a Juan de Palafox (1642), convencido también de que había sido alentado por los hijos de San Francisco. ${ }^{29}$ El prelado-virrey relataría en un memorial al conde de Salvatierra, que Nuevo México era un lugar sometido a aquellos misioneros, que en un principio se habían ocupado de la cristianización, pero que luego, al tener asumidas las competencias que correspondían a los obispos y las de Inquisición y Cruzada, sin que existiese otro gobierno eclesiástico, se habían enfrentado a los gobernadores, como al mencionado Luis de Rosas y a su sucesor Juan Flores de Sierra y Valdés..$^{30}$

Las tensiones entre los seráficos y los obispos de Durango, cuando estos quisieron hacer valer su poder, se convirtieron en una constante. En 1667 el cabildo secular de Santa Fe había elevado sus quejas al prelado durangués, Juan de Gorozpi, quejándose de los abusos de los custodios

25 Vázquez, 2004, 89.

26 AGI, México, 33, L. 2, 137-138, «Información del virrey al rey sobre propuesta de obispado para Nuevo México», México, 22 de julio de 1637. Hacket, 1937, 89-92.

27 AGI, México, 35, N. 17, «Carta del virrey marqués de Cadereyta», México, 24 de noviembre de 1640 .

28 Hacket, 1937, 116.

29 Este problema se encuentra en el legajo existente sobre la actividad de Palafox, AGI, Patronato, 244, R. 7, 239, «Levantamiento de Nuevo México y proceder del obispo Palafox», 1644.

30 Palafox, 2006, 159-161. 
franciscanos y solicitándole que pusiese un vicario. ${ }^{31}$ No gustó aquello al comisario general Hernando de la Rúa, que al año siguiente se quejaba y pedía que se le prohibiese al prelado actuar en tal sentido. ${ }^{32}$

Posteriormente sería el obispo Bartolomé García de Escañuela, el que en 1677 discrepó de la visita del comisario franciscano Antonio de Valdés, ${ }^{33}$ pero tampoco los frailes quisieron aceptar la visita que él mismo inició a Nuevo México, en la que, por su delicado estado de salud, solo pudo llegar hasta El Paso.

Después de aquello, el levantamiento de los indios pueblo (16801692) no zanjó la polémica del todo, a pesar de la violencia desatada contra los españoles en general.

De hecho, en aquella revuelta murieron 21 franciscanos y prácticamente todos los españoles abandonaron el territorio. El obispo de Durango, a pesar de los acontecimientos, decidió seguir nombrando vicario para Nuevo México, pero para no entrar en conflicto con los frailes designó en 1681 al custodio fray Francisco de Ayeta. ${ }^{34}$ En esa misma línea estuvo otro prelado, Manuel de Herrera, que en 1688 nombraba como vicario al también custodio fray Francisco de Vargas. ${ }^{35}$ Evidentemente eran tiempos difíciles en los que el clero secular difícilmente iba a aceptar cargos en un lugar de guerra, en el que ni siquiera podían asentarse. Acabada la sublevación de los pueblo, los franciscanos se vieron favorecidos por los nuevos gobernadores con las promesas de Diego de Vargas a fray Francisco Corvera, ${ }^{36}$ al igual que por Pedro Rodríguez Cubero. ${ }^{37}$ Pero la guerra de Sucesión llevó al poder al partidario francés, Felipe $\mathrm{V}$, que era mucho más proclive a favorecer al clero secular.

A pesar de todo, en el siglo XVIII, los frailes continuaron en su afán por crear una jurisdicción eclesiástica, alegando que era un territorio dema-

31 Biblioteca Nacional de México (en adelante BNM), Fondo Reservado. Colección Archivo Franciscano (en adelante FR.CAF), 11/184.1, 1-2, «Carta del cabildo de Santa Fe al obispo Juan de Gorozpi, quejándose de los custodios», 1667.

32 Ibidem, 11/185.1, 1-7. «Representación del comisario general de los franciscanos al virrey», México, 10 de febrero de 1668.

33 Vázquez, 2004, 88.

34 BNM, FR.CAF, 12/198.2, 3-6, «Título de vicario y juez eclesiástico a favor de fray Francisco de Ayeta», 1681.

35 Ibidem, 12/205.1, 1-2, «Nombramiento del obispo de Nueva Vizcaya a fray Francisco de Vargas como vicario y juez eclesiástico», Durango, 24 de octubre de 1688.

36 Ibidem, 22/454.1, 1, «Fray Francisco Corvera solicita al gobernador Diego de Vargas sitio para iglesia y convento en la villa de Santa Fe», Santa Fe, 14 de septiembre de 1692.

37 Kesell, Hendricks y Dodge, 2000, 404-408. 
siado alejado de Durango como para ser controlado por sus prelados y con el fin de mantener su independencia respecto de las injerencias de los obispos. Estos, sin embargo, para hacer patente su autoridad, recurrieron a seguir disponiendo de vicarios foráneos, a lo que también se opondrían los franciscanos, que habían conseguido en 1694 que los obispos no pudiesen usar de ellos en sus diócesis y que incluso retirasen los ya nombrados. ${ }^{38}$ Pero, como mencionamos, la nueva monarquía tenía otras pretensiones, entre las que estaba la de mantener un control más efectivo sobre la Iglesia, lo que a la vez favorecía las pretensiones de los prelados frente al clero regular. Así, en el asunto de los vicarios, el nuevo monarca en una cédula dirigida a todos los prelados de las Indias, de 7 de septiembre de 1701, alentaba al nombramiento de tales vicarios. ${ }^{39}$ En otra de 7 de diciembre de 1719, encargaba a los diocesanos visitar las misiones de los regulares; y en otra de 30 de julio de 1721, ordenaba poner visitadores en aquellos lugares demasiado alejados de la cabeza episcopal, como era el caso de Nuevo México.

Como es sabido, las disposiciones reales no necesariamente suponían su cumplimiento y los franciscanos de Nuevo México siguieron siendo reticentes al poder de los prelados. Sería el obispo Benito Crespo y Monroy (1723-1737) quien definitivamente intentase hacer valer su poder, con una visita que inició en 1725, lo que provocó, como casi siempre, las protestas de los frailes. Incluso aquel mismo año, y para no herir la susceptibilidad de los franciscanos, el prelado había nombrado vicario y juez eclesiástico al vicecustodio de las misiones de El Paso, fray Salvador López.$^{40}$ Este sería removido en 1728 por el comisario de su Orden, poniendo en su lugar como juez eclesiástico al custodio de Nuevo México, ${ }^{41}$ a pesar de que fray Benito Crespo le recordara sus derechos sobre aquella custodia en territorios de su diócesis, ${ }^{42}$ lo mismo que se lo haría saber al virrey marqués de Casafuerte, en $1731,{ }^{43}$ un año después de haber decido hacer de nuevo la

38 Archivo General de la Nación, México (en adelante AGN), Bienes nacionales, 1285, N. 23.

39 AGI, Indiferente, 431, L. 45, 175-178, «Real Cédula a los arzobispos y obispos de Perú y Nueva España para que observen lo dispuesto acerca de nombrar visitadores para las doctrinas de regulares y poner vicarios foráneos», Madrid, 4 de septiembre de 1701.

40 BNM, FR.CAF, 14/240.2, 3-4, «Nombramiento de vicario y juez eclesiástico a favor de fray Salvador López», El Paso, 9 de agosto de 1725

41 Ibidem, 14/246.2, 3, «Carta del visitador franciscano al obispo de Durango, comunicándole que ha sido removido fray Salvador López», El Paso, 6 de julio de 1728.

42 Ibidem, 14/246.1, 1-2 y 14/246.3, 4-7.

43 Ibidem, 14/248.1, 1 y 14/253.1, 1-7, «Representación del obispo de Durango al virrey, probando sus derechos sobre las misiones de Nuevo México», Durango, 28 de abril de 1731. 
visita de la provincia, ${ }^{44}$ a pesar de que el custodio franciscano, fray Andrés Varo, hubiese intentado disuadirle. Pero el prelado decidió no prestar oídos, si no se le presentaban los supuestos privilegios de la custodia franciscana de Nuevo México. ${ }^{45}$ Lo cierto es que, saliendo de Chihuahua, se encaminó a El Paso y de allí a Albuquerque y Santa Fe. ${ }^{46}$ Ante aquella situación, los frailes, en una reunión celebrada en esa última villa el 18 de agosto, decidieron abandonar la provincia para no provocar un cisma, lo que se comunicó al gobernador Juan Domingo de Bustamante. ${ }^{47}$

No llevaron a efecto su amenaza, pero los franciscanos seguían manifestando sus protestas y pensando en la solución de crear un obispado ${ }^{48}$ tal y como lo solicitaba el comisario general, Francisco Alonso González, tras aquella turbadora visita del obispo. ${ }^{49}$ Crespo, amén de esto, y contra los intereses de los frailes, había colocado como su vicario en Santa Fe a Santiago Roybal, a pesar de las protestas del procurador general, que insistía en que la custodia de Nuevo México no era jurisdicción del prelado. ${ }^{50}$ Lo cierto es que Roybal se mantuvo hasta 1731, en que se le destinó a la localidad de El Paso y se nombraba como nuevo vicario a José Bustamante. ${ }^{51}$

Las tensiones hicieron que desde España se pidiese al prelado, el 1 de octubre de 1732, que retirase a su vicario a la vez que se pedía al virrey que mediase en la discordia. ${ }^{52}$ Crespo, de todos modos, no estaba dispuesto a ceder y nadie pudo evitar que iniciase otra visita en 1734, de lo que, como era de esperar, se volvieron a quejar los franciscanos a su provincial..$^{53}$

44 Sobre los problemas de Benito Crespo con franciscanos puede verse las ampliaciones de Valenzuela, 1776, T. II, L. IV, c. XVIII.

45 BNM, FR.CAF, 14/249.2, 3, «Decisión del obispo de Durango de seguir adelante en la visita de Nuevo México», El Paso, 10 de julio de 1730.

46 Andrade, 1899, 186 y ss.

47 BNM, FR.CAF, 14/249.3, 4-5, «Acta de la reunión convocada por fray Andrés de Varo para considerar los problemas de la provincia», Santa Fe, 17 de agosto de 1730 y 14/249.4, 6, «Comunicación de fray Andrés de Varo al gobernador con la decisión de abandonar aquella custodia», Santa Fe, 18 de agosto de 1730.

48 Vázquez, 2004, 90.

49 BNM, FR.CAF, 12/213.1, 1-13, «Representación del comisario general de los franciscanos sobre los problemas con el obispo de Durango», (s.l y s.f).

50 Ibidem, 13/216.1, 1-8, «Memorial del comisario general de los franciscanos exponiendo que la custodia de Nuevo México no pertenece al obispo de Durango», s/l., 1731.

51 Domínguez, 1975, 242.

52 BNM, FR.CAF, 14/251.1, 1-10, «Real despacho para que el obispo de Durango retire al juez o vicario foráneo de las misiones de Nuevo México», Sevilla, 1 de octubre de 1732.

53 Ibidem, 14/258.3, 5, «Carta informando al provincial franciscano de la visita que pretende hacer el obispo de Durango», Senecú, 11 de julio de 1734. 
El sucesor de aquel prelado, Martín de Elizacoechea, también realizó una visita a Nuevo México en 1737-1738, siempre con la oposición seráfica. Al finalizarla, escribió el 17 de mayo al comisario general, dando cuenta de la poca religiosidad de algunos de sus frailes y de su desconocimiento de la lengua de los naturales. ${ }^{54}$ Como con su antecesor, los hijos de San Francisco se negaban a aceptar un vicario episcopal en Santa Fe y de nuevo surgió la amenaza de abandonar la provincia, tal y como lo comunicó el custodio Miguel Menchero, en $1741 .{ }^{55}$ La amenaza tampoco se llevó a efecto, pero en cambio el mencionado custodio volvía a insistir, en 1748, en la creación de una diócesis, en un escrito que se le atribuye y que se tituló Instrucciones para la erección de obispado en Nuevo Mexico. ${ }^{56} \mathrm{La}$ actividad tanto de Crespo como de Elizacoechea, la recogería Valenzuela en una obra editada en Madrid en 1738..$^{57}$

Las proposiciones de obispado no solo tuvieron que ver con el control que querían mantener los franciscanos, sino que hubo otras proposiciones más centradas en una mejor administración espiritual y temporal, como la de Matías de la Mota Padilla, que propuso sin éxito la creación de una diócesis que comprendiese Nuevo México, Texas y Coahuila, lo que permitiría un acercamiento del pastor a sus feligreses. ${ }^{58}$

A mediados del siglo XVIII la actividad secularizadora de la centuria se hizo más evidente. Por cédula de 1 de febrero de 1753 se ordenaba secularizar todas las doctrinas o misiones de indios bien cristianizados. Fue entonces el obispo Romeral y Tamarón el que pretendió restar poder a los franciscanos de Nuevo México, con su visita de $1760^{59}$ y colocando a Santiago Roybal como su vicario en Santa Fe, amén de pretender otros dos vicariatos en Albuquerque y Santa Cruz de la Cañada.$^{60}$ Era obvio que no existía suficiente clero secular como para hacerse cargo al completo de Nuevo México, pero tanto el obispo como su vicario pretendían controlar, al menos, las cuatro grandes villas de españoles: El Paso, Santa Fe, Albuquerque y Santa Cruz. De hecho el prelado solicitó la secularización

54 Ibidem, 15/260.6, 10-12, «Carta del obispo de Durango al comisario franciscano sobre lo que ha visto en las misiones», Durango, 17 de mayo de 1738.

55 Ibidem 28/528.3, 6, «Carta del custodio de Nuevo México al comisario general franciscano informándole de que pedirá al obispo que retire sus jueces», Nuevo México, 17 de noviembre de 1741.

56 Steele, 1988, 212. Vázquez, 2004, 91.

57 Valenzuela, 1738

58 Mota Padilla, 1870, 280.

59 Sobre esta vista nos dejó la descripción, en Tamarón, 1937, 327-360.

60 Ibidem, 335-336. 
de aquellos lugares en 1765, a lo que se opuso el comisario general franciscano, como se lo hizo saber al virrey marqués de Croix, en $1768 .{ }^{61}$ No se debe olvidar que en el ínterin Carlos III, el 30 de julio de 1766, había mandado que los curatos y doctrinas de los regulares fueran asignándose a los seculares. Con todo esto, el marqués reconocería las pretensiones de Tamarón en 1767, pero hubo de retractarse al año siguiente, puesto que, al convocarse la oposición para aquellos curatos, no hubo ningún pretendiente del clero secular. ${ }^{62}$ Aun así volvió Tamarón a solicitar lo mismo al gobernador de Sonora y Sinaloa, Juan de Pineda, en 1768, para secularizar cuatro misiones de los antiguos jesuitas. ${ }^{63}$ Precisamente la expulsión de la Compañía de Jesús había supuesto un respiro para los franciscanos del norte de la Nueva España, puesto que quedaron casi como los únicos evangelizadores del norte, de los que no se podía prescindir.

La creación de la Comandancia General de las Provincias Internas (1776) hizo que se intensificara la promoción del clero secular frente al regular, así como se insistía en la proposición de una nueva diócesis en el norte de la Nueva España, lo que apoyaban tanto José de Gálvez como Teodoro de Croix. Este último propuso a Gálvez el 26 de enero de 1782 la creación de tres diócesis: una formada por Sonora y California; otra por Coahuila y Texas y una tercera por Nueva Vizcaya y Nuevo México, ${ }^{64}$ lo cual, como veremos, daría sus frutos con la creación de las diócesis de Nuevo León y de Sonora (1777-1779). Aquellos intentos secularizadores los representó de una manera muy especial el gobernador Juan Bautista Anza, que en 1781 se lanzó a una campaña contra los franciscanos, pero que, como en tiempos de Tamarón, se encontró con un clero secular, con el que no se podía contar para la suplencia ni en número ni en disposición para afrontar los problemas de tierras de frontera, con los peligros que allí se cernían. ${ }^{65}$ No menos duro fue Fernando Chacón (1794-1804), que acusó a los frailes en un informe de maltratadores de los indios, lo que sirvió para intentar acelerar el proceso secularizador. ${ }^{66}$

61 BNM, FR.CAF, 16/300, 1-22, «Representación del comisario franciscano al virrey, oponiéndose a la pretensión del obispo de Durango», México 3 de octubre de 1766.

62 Vázquez, 2004, 91-92.

63 BNM, FR, CAF, 16/303.7, 12-13, «Carta del obispo de Durango al gobernador de Sonora y Sinaloa», Sinaloa, 22 de julio de 1768.

64 AGI, Guadalajara, 268, «Correspondencia del Comandante General de las Provincias Internas», 26 de enero de 1782.

65 Hendricks, 1998, 111-115.

66 Flagler, 1997, 112. 
En general, casi todos los gobernadores, atentos a la política de la Corona, no veían con buenos ojos el dominio de una Orden religiosa de un espacio concreto, como sucedía en Nuevo México. En cuanto al control religioso era algo parecido a lo que había sucedido con los jesuitas en las misiones de Paraguay, por lo que tras su expulsión se habían entregado a franciscanos, dominicos y mercedarios, tratando de evitar el control omnímodo de una orden. ${ }^{67}$ Todo ello sin olvidar que era mucha la población que criticaba con frecuencia la actitud de los frailes, ${ }^{68}$ incluidos los indios, por los altos aranceles que imponían por impartir los sacramentos y por la utilización de demasiados sirvientes. ${ }^{69}$

En 1789 la proposición de un nuevo obispado vendría del propio prelado de Durango, Francisco Gabriel de Olivares y Benito (1786-1812). ${ }^{70}$ En realidad, en un intento de racionalizar la organización eclesiástica del territorio abogaba por la creación de cuatro mitras: las Californias, Sonora, Nuevo México y Nueva Vizcaya. La dotación para el de Nuevo México sería a través de los diezmos, que desde el 5 de marzo de 1799 se hallaban cedidos por el obispo para conseguir la desmembración. El propio virrey Miguel José de Azanza, en 1800, también era favorable a la erección de una diócesis,${ }^{71}$ pues parecía imprescindible la presencia de prelados en el norte de la Nueva España y en concreto en Nuevo México. ${ }^{72}$ Era obvia aquella pretensión en un territorio tan inabarcable, al que las visitas episcopales raramente llegaban, pues eran 400 leguas las que separaban Santa Fe de Durango, por lo que Nuevo México solamente había sido visitado por tres prelados, el último de ellos Tamarón y Romeral, en 1760. Después de el habría que esperar hasta la visita del obispo José Antonio Zubiria, en 1833.

A pesar del deseo de sustituir a los franciscanos por clérigos, en el tiempo que nos ocupa fue una labor casi imposible, tanto por el número como por la disposición. En lo numérico hasta 1802 raramente hubo más de un clérigo secular y en ese año fueron tres, mientras que los franciscanos llegaron a moverse numéricamente en torno a la veintena ${ }^{73}$ en los años más críticos de la presencia española. En 1805 había tres parroquias y 12

67 Weber, 2007, 178-179.

68 Gutiérrez, 1993, 371-375.

69 González, 1991, 274

70 AGI, Guadalajara, 561, «Expediente sobre el establecimiento de un obispado y semanario en Santa Fe», 1812-1817.

71 Torre Villar, 1960, 77-78.

72 Twitchell, 2008, 408-409 y 413.

73 Wright, 1998, 238. 
misiones. Navarro y Noriega en 1810 daba para Nuevo México 28 misiones y ningún curato. ${ }^{74}$ Esto hizo que los conflictos de jurisdicción entre franciscanos y obispos debilitaran mucho la posición de estos últimos, y que la pretendida erección de un obispado neomexicano estuviese en relación directa con esos conflictos, puesto que los franciscanos pretendían mantener su poder a través de una fundación adscrita a su Orden, que los liberara de otras intromisiones. También es cierto que a medida avanzó el siglo XVIII y sobre todo a partir del reinado de Carlos III se pensó en una diócesis más por intereses de administración eclesiástica que de conflictos, aunque estos se mantuvieran. Además los franciscanos también pasaron en el siglo XVIII por una crisis de vocaciones, a pesar del funcionamiento de sus colegios de Propaganda Fide, y su número no permitía abordar todas las necesidades del territorio.

En toda aquella pretensión de erección de un obispado neomexicano también se había planteado la solución de un obispo auxiliar. Así lo propuso Juan de Oliván, que había pasado como oidor de Guadalajara en 1712,75 al que se debe el mapa del norte de la Nueva España, de $1717,{ }^{76}$ y que sugirió tal idea al virrey marqués de Casafuerte el 12 de julio de $1724 .{ }^{77}$ Esta solución la propondría también años más tarde el obispo de Guadalajara, Antonio Alcalde, en 1773, para los territorios bajo su dependencia en el norte, por la imposibilidad de administrarlos, lo que parece que tuvo buena acogida, pues al año siguiente se le contestaba diciendo que su proposición se había pasado al Consejo. ${ }^{78}$ Sin embargo no parece que esto llegara a calar en lo referente al territorio que nos ocupa.

\section{El planteamiento definitivo en las Cortes de Cádiz}

La respuesta a las necesidades de crear diócesis en el norte de la Nueva España, tal y como la llegaron a plantear José de Gálvez y Teodoro de Croix, era un asunto paralelo a la creación de la Comandancia de las

74 «Noticias de la Nueva España en 1805», 27. Olmos, 209.

75 AGI, Contratación, 5466, N. 2, R. 30, «Información y licencia de pasajero de Juan Oliván y Rebolledo, oidor de Guadalajara», 29 de agosto de 1812.

76 AGI, Mapas y planos, México, 110, «Mapa presentado por don Juan Oliván al virrey el 18 de diciembre de 1717 ».

77 BNM, FR, CAF, 26/502.14, 79v-84, «Informe del gobernador de Nuevo México al virrey», México, 12 de julio de 1724 .

78 AGI, Guadalajara, 250 y 340. 
Provincias Internas, en un intento por controlar a la Iglesia, dentro de la tónica general que representaba el despotismo ilustrado, que no veía con buenos ojos la autonomía de las órdenes religiosas en determinados espacios, sobre todo de misión. En aquellos dos siglos, lo que había sido una fricción continua entre los obispos y los franciscanos de Nuevo México por el control del territorio en asuntos religiosos, acabó por convertirse en un asunto de gobernabilidad, en que hubo grandes injerencias del poder civil, siempre dispuesto, sobre todo a partir de Carlos III, a convertir al estado en el eje de la política religiosa, con todo lo que ello implicaba, teniendo su culmen en las Cortes de Cádiz.

Los pasos iniciales de la reorganización eclesiástica del norte de la Nueva España, en relación con la Comandancia, fue la creación de dos diócesis, que se repartieron prácticamente todos los territorios, desde California hasta Texas, manteniéndose Nuevo México bajo la jurisdicción episcopal de Durango. Así, el 15 de diciembre de 1777 se erigió la diócesis de Nuevo León por la bula Relata semper, de Pío VI, ${ }^{79}$ con sede en Linares; pero que por expreso permiso real se trasladaría en 1789 a Monterrey. ${ }^{80}$ Esta comprendía los territorios de Nuevo León, Coahuila, Tamaulipas y Texas.

El 7 de mayo de 1779 el mismo Pío VI extendía la bula Inmensa Divinae Pietatis Charitas, por la que quedaba establecido el obispado de Sonora, con sede en Arizpe y cuyo primer obispo, por expreso deseo de Gálvez, sería preconizado en 1780 en la figura del franciscano Antonio de los Reyes, aunque no partiría hacia su diócesis hasta dos años más tarde ${ }^{81}$ Comprendería los territorios de Sonora y Sinaloa, desgajados de Durango, y las Californias, escindidas entonces de Guadalajara.

Nuevo México, por tanto, quedaba como un espacio aislado en medio de las nuevas diócesis y sus pretensiones de control eclesiástico ya no podían ir más allá de su territorio. Aún así, los deseos de contar con obispado propio se mantuvieron y se plasmarían en las peticiones hechas por su diputado en las Cortes de Cádiz, Pedro Baptista Pino, en el informe leído el 20 de noviembre de 1812. Aquel discurso se imprimió en la Imprenta del Estado Mayor, en Cádiz, en ese mismo año. ${ }^{82}$ La forma se la había dado el

79 Sobre este obispado y la mencionada bula puede verse Tapia, 1988, 1-103.

80 Sobre la creación de este obispado puede verse Portillo, 2002, 575 y ss.

81 AGI, Contratación, 5525, N. 8, R. 5, «Expediente y licencia de pasajeros a Indias de personas al servicio de fray Antonio de los Reyes», 18 de marzo de 1782.

82 Nos atenemos a la actual edición de Pino y López Cancelada, 2007, ya que es la primera que aparece con el nombre de los dos autores. 
periodista Juan López Cancelada, desterrado de México, donde había sido editor de La Gazeta entre 1805-1809. Desde su llegada, debido a la ocupación francesa, se había establecido en Cádiz, donde intervino con frecuencia en muchos asuntos americanos y se enfrentó a muchos diputados de aquellas latitudes, a veces a través de su periódico El Telégrafo Americano, publicado en la ciudad de las cortes entre octubre de 1811 y marzo de $1812 .^{83}$

La exposición del diputado Pino fue organizada por López Cancelada, aunque sería el neomexicano quien le aportara los datos concretos. Es más, el periodista, para que no quedase duda de la autoría, recurrió a un acróstico en la página. 42 del original, donde, si se enlazan las mayúsculas tras cada punto y seguido se lee: «D. Juan López Cancelada $»{ }^{84}$ Él mismo dio a conocer este hecho en un folleto publicado en 1818 bajo las mayúsculas de autor J.M.C., ya que fue muy proclive a alterar su nombre y/o sus iniciales. ${ }^{85}$

En aquel escrito, en el que se tocaban varios puntos relativos a Nuevo México, Pino y López Cancelada exponían las razones por las que se solicitaba la nueva diócesis en las Cortes. En primer lugar se reconocía la enorme distancia de 400 leguas que había entre Santa Fe y Durango, con un camino difícil y peligroso, por lo que tan solo había recibido la visita de tres obispos en aquellos dos siglos: Benito Crespo, Martín de Elizacoechea y Pedro Tamarón y Romeral. En consecuencia, Pino alegaba la tristeza que le producía el que con los 10.000 pesos de diezmos que aportaba Nuevo México, no se dejase ver por aquella provincia al obispo de Durango; de hecho, él mismo manifestaba que no sabía como vestían los prelados hasta que no llegó a Cádiz. ${ }^{86}$

Otro motivo que se aducía era la enorme extensión, que alcanzaba las 3.500 leguas cuadradas, en las que se ubicaban 40.000 habitantes organizados en 26 pueblos de indios y 102 plazas de españoles. Por último, se alegaba que Nuevo México producía anualmente en diezmos al obispado de Durango la nada despreciable cantidad de 10.000 pesos.

Se aducía igualmente que tanto las poblaciones de indios como las plazas de españoles se administraban por 22 religiosos franciscanos. Solamente en El Paso y en Santa Fe se contaba con párrocos clérigos, ya

83 Existe edición actual facsimilar publicada por la Universidad de León, 2008

84 Véase en Pino y López, 124-125.

85 López Cancelada, 1816, 6.

86 Algunos autores han mantenido que Pino había estudiado leyes. Parece que esto lo contradice, pues el haber estado en alguna universidad novohispana le habría familiarizado con la presencia episcopal. 
que, como vimos, el proceso de secularización borbónico no había producido los efectos deseados, ni siquiera durante el gobierno de Fernando Chacón y su empeño por ello (1794-1804), aunque sí se hubiese reducido la presencia de franciscanos, que en tiempos de Joaquín del Real Alencaster (1804-1807) llegó a ser de tan solo ocho, sin haber sido sustituidos por el clero secular. No es de extrañar, por tanto, que los frailes se volviesen a recuperar numéricamente. ${ }^{87}$

Amén de lo anterior, Pino y Cancelada justificarían también la necesidad del obispado en cuestiones meramente prácticas y de organización eclesiástica, pues Nuevo México parecía un lugar abandonado de la mano de Dios, ya que la escasez de párrocos no permitía atender todo el territorio ni los feligreses podían trasladarse largas distancias para cumplir con sus preceptos.

Pero además de aquello seguían existiendo otros problemas que hemos visto con anterioridad. Así, por entonces se volvía a traer a colación el problema de los vicarios, de los que no se podía disponer en los lugares más alejados, porque las rentas no alcanzaban para ello. La explicación que se daba en este sentido era que la asignación anual de cada religioso al frente de una parroquia era de 330 pesos anuales, ${ }^{88}$ cantidad con la que, según el obispo de Durango, los clérigos no podrían subsistir y atender sus necesidades, como eran las criadas y los aparejadores de sus caballos; así como tampoco mantener el altar de sus iglesias. ${ }^{89}$ Incluso en los lugares más habitados - las villas de Alburquerque, Santa Cruz de la Cañada y Santa Feno había más renta que las obvenciones o pie de altar.

Toda aquella problemática suponían el diputado y el periodista que podía solucionarse con la creación de una diócesis y la presencia de un obispo propio para aquel territorio. Pues, además de las mencionadas carencias materiales, se podrían implementar las espirituales, como la administración del sacramento de la confirmación, que no se impartía desde la visita de Tamarón, en 1760; incluso se evitarían los amancebamientos de quienes necesitaban de dispensa eclesiástica, lo que era bastante frecuente en Nuevo México, donde la endogamia de determinadas familias era más que evidente..$^{90}$

87 Wright, 1988, 226-227. Flagler, 1997, 112

88 Flagler, 1997, 95.

89 AGI., Estado, 43, N. 40, 9-10, «Recomendaciones del obispo de Durango al gobernador de Nuevo México», Durango, 7 de julio de 1810.

90 Sobre esto es interesante ver la obra de Chávez, 1992. 
Las soluciones que proponían los autores eran, por un lado el establecimiento en Santa Fe de la cabeza de la diócesis; pero además de esto, muy de acuerdo con la tradición ilustrada, la creación de un colegio seminario de estudios mayores, ${ }^{91}$ así como escuelas públicas para la enseñanza de la juventud..$^{92}$ Esto podría resultar contradictorio con lo que sucedía a finales del siglo XVIII en otros lugares de las Indias, donde en la educación hubo tendencia a un mayor control de las autoridades civiles; pero en los lugares de frontera tal labor hubo que reservarla a menudo para la Iglesia, pues no todos los civiles con formación estaban dispuestos a adaptarse a unos condiciones de vida no demasiado favorables. Por ello, un seminario suponía un avance en lugares que pocas aspiraciones podían tener más allá de alguna pequeña escuela o de formadores particulares.

Pino se movía entre la tradición y la modernidad, en este último caso, probablemente incitado por López Cancelada. Así, junto a la pretensión de una diócesis planteó aquella idea que habían tenido los propios franciscanos, que los prelados debían ser de su Orden, porque «están los habitantes tan acostumbrados a ver este hábito, que cualquiera otro, no sería, quizá, bien admitido». ${ }^{93}$

Las proposiciones de Pino tuvieron una buena acogida en las Cortes, que solicitaron a la Comisión Ultramarina para que informara sobre estos aspectos, la cual dio su contestación favorable el 21 de enero de $1813 .{ }^{94}$ Tras ello, por el decreto CCXVII, de 26 de enero del mismo año, se decidía erigir el obispado con las firmas de Miguel Antonio de Zumalacárregui, como presidente, y como secretarios Florencio Castillo y Juan María Herrera. Sin embargo, aquel no era el paso definitivo, pues se necesitaba completar otras informaciones para hacer efectiva la erección. Especialmente relevante era la demarcación territorial, para lo que las Cortes solicitaron a las máximas autoridades civiles y religiosas de Nuevo México y Nueva Vizcaya, que procedieran al deslinde. ${ }^{95}$ Se recordaban, incluso, los trámites necesarios en el proceso: era prioritario pedir a la Santa Sede el decreto pontificio, por medio del ministro plenipotenciario,

91 Hacia 1812 se iniciaron los trámites para la fundación de este seminario en la ciudad de Santa Fe, como se recoge en un expediente del AGI, Guadalajara, 561. Con la llegada de Fernando VII se paralizó el proceso. Navarro, 1965, 374.

92 Pino, López, 2007, 180.

93 Ibidem, 184.

94 Toda la documentación que nos informa de estos hechos se encuentra en el AGI, Guadalajara, 561.

95 Colección de los decretos, 1829, 78. 
a lo que no podían negarse en Roma por la cuestión de la concesión papal a los Reyes de España; se suponía también que se debían enviar despachos o cédulas a los dos obispos más cercanos de la nueva diócesis, que, junto con el vicepatrono regio, debían proceder a la división; se debían mandar igualmente cédulas a los obispos afectados por la desmembración, al metropolitano al que correspondiese la nueva mitra, al gobernador de la provincia, al del distrito y al virrey. Entretanto se debía pasar a consulta y nombrar un prelado y, si este aceptaba, se pedían las bulas a la Santa Sede.

Evidentemente este proceso no se realizó tal y como se describía. Lo primero que se planteó fueron cuestiones burocráticas internas, habida cuenta de las alteraciones en la administración que se habían producido. $\mathrm{La}$ Regencia, en ese sentido, comenzó por solicitar a la Comisión Ultramarina de las Cortes información sobre quién debía emitir las cédulas de creación del obispado, si el Consejo de Estado o la Consejería de Gracia y Justicia. Aquella Comisión, formada por Zumalacárregui, José María Gutiérrez de Terán, José Antonio Navarrete, Pedro Antonio Aguirre y Antonio Larrazábal opinó que debía ser la Consejería de Gracia y Justicia, puesto que el Consejo de Estado era solamente consultivo. ${ }^{96}$

Otro problema fue el de la división territorial y quién debía hacerla. La Comisión, recurriendo a las Leyes de Indias, a las reflexiones de Ciriaco Morelli, profesor de la Universidad de Córdoba de Tucumán, ${ }^{97}$ y al mismo Solórzano, planteó que era algo que atañía directamente al monarca, por lo que las cédulas para establecer la división debían enviarse a quien en aquellos territorios representase el real patronato y que este debería trabajar en «anuencia» con el obispo de Durango.$^{98}$ En la sesión de las Cortes donde se planteó este problema intervino Ramos Arizpe, que veía la necesidad de que el decreto de erección se hiciese en uno o dos años «y no pasen diez o veinte»; para ello se debía sustituir la mencionada «anuencia» del prelado de Durango por la de «intervención»; es decir, que era conveniente que el obispo interviniese, pero no que fuera necesaria su anuencia. Frente a esto el diputado Juan de Lera y Cano recurrió al derecho canónico y, por tanto, creía necesario que se oyese al obispo afectado y que se comprobase la existencia de rentas. Ramos Arizpe alegó entonces que la diócesis duran-

96 Diario de sesiones. Sesión del 30 de abril de 1813.

97 Seudónimo de Domingo Muriel, jesuita al que alcanzó la expulsión. Fue autor, entre otras obras de los Rudimenta juris naturae et gentium. Publicada en Venecia en 1791.

98 Diario de sesiones. Sesión del 30 de abril de 1813. 
guesa estaba en sede vacante ${ }^{99}$ y por ello «no hay rey ni Roque que impida hacerse esa desmembración del modo que ya he dicho». Habló también el diputado por Maracaibo, José Domingo Rus, alegando su experiencia en la división de las diócesis venezolanas y apoyó las tesis de Arizpe. Tomás Aparicio Santiz, por otro lado, pensaba como Lera, que no se podía quitar jurisdicción al obispo que la ejercía, porque eso no correspondía a la autoridad real. Rus le respondió que la división de una diócesis no era una cuestión espiritual sino solo temporal y, por tanto, no afectaba a la Iglesia. Por la Comisión que había aprobado el dictamen habló Larrazabal ratificando que la licencia para erigir un obispado en Indias era un derecho real. ${ }^{100}$

Visto lo anterior, no le faltaba razón a Ramos Arizpe cuando sospechaba del retraso, como lo volvió a recordar meses más tarde, cuando en una alusión que hizo José Argüello al obispado de Nuevo México, contestó el representante por Coahuila que no era «tan crédulo en cédulas, por bien selladas que vayan». ${ }^{101}$

Amén de esto era necesario también proponer sujetos para la mitra, por lo que el 14 de mayo de 1813 se comunicaba que la Regencia había resuelto que el Consejo de Estado procediera a proponerlos, cosa que parece que nunca se hizo mientras el diputado Pino se mantuvo en Cádiz, donde cesó como tal el 29 de septiembre de $1813 .{ }^{102}$

\section{Los últimos intentos y el fracaso}

Las Cortes de Cádiz parecían haber sido la etapa final de aquel antiguo proceso episcopal de Nuevo México. La buena acogida inicial de la proposición de Pedro Baptista Pino se fue disolviendo en los meses siguientes en asuntos burocráticos. El propio diputado de Nuevo México tuvo que soportar las burlas de su gente, que le acusaba de inacción en la asamblea constituyente y que hizo famosa la frase «Don Pedro del Pino fue, don Pedro del Pino vino». En realidad, el fracaso tenía mucho más que ver con el regreso de Fernando VII, que se produjo el 22 de marzo de 1814,

99 Lo estuvo desde el final de la prelatura de Francisco Gabriel de Olivares y Benito, el 26 de febrero de 1812, hasta el nombramiento de Juan Francisco Castañiza Larrea, el 18 de diciembre de 1815.

100 Diario de sesiones. Sesión del 30 de abril de 1813.

101 Diario de sesiones. Sesión del 10 de junio de 1813.

102 Archivo del Congreso de los Diputados (ACD), Documentación electoral, 3, n. $^{\circ} 30$. 
y con el decreto de abolición de la Constitución de Cádiz el 4 de mayo, cuya información llegaba a México el 17 de agosto del mismo año.

Con el sexenio absolutista muchas de las cuestiones planteadas en las Cortes se pusieron en entredicho. En el caso del obispado de Nuevo México, aunque no hubo una negativa firme a su creación, las cosas se fueron prolongando en un interminable proceso de informaciones, que se mantuvieron hasta la independencia ${ }^{103}$ pues no parece que hubiese una intención clara por alterar el panorama administrativo de la Iglesia novohispana en un momento de dudas de todo tipo, pero en que tampoco interesaba plantear una negativa contundente para no provocar el descontento de una población esperanzada en tener su diócesis, con todo lo que ello suponía en la época, pero que al mismo tiempo no estaba ajena al proceso independentista.

Sobre la cuestión de límites ya vimos el interés que se había despertado con anterioridad y al que debió responder el comandante general de las Provincias Internas Occidentales, Bernardo Bonavia (1813-1817). Pero su respuesta llegó a España cuando Fernando VII ya ocupaba el trono. Decía el Comandante que los límites de Nueva Vizcaya y Nuevo México se hallaban en El Paso y el río Grande, por lo que no era necesario hacer una demarcación más concreta del obispado, que coincidiría con las divisiones provinciales, tal y como lo había acordado con el canónigo doctoral de Durango. Los problemas se podían plantear con otras provincias, pero llegaron a la conclusión de que los desiertos que separaban a Nuevo México de Texas y de Sonora no hacían necesaria una demarcación concreta, que podría llevarse a cabo cuando se delimitasen las provincias, como mandaba la Constitución y se recogía en el capítulo II.

En el fondo, todo lo que se había planteado y se seguía planteando era la supeditación de la administración eclesiástica al Estado, en aquella línea que habían defendido muchos preilustrados e ilustrados tanto de España como de sus posesiones.

Bonavia, respondiendo al problema económico, manifestaba que tanto para el seminario como para el obispado solamente se podía contar con los diezmos, que él mismo, de manera previsora, ya había mandado retener en las cajas de Chihuahua a partir del 16 de junio de 1814, sin perjuicio del derecho que a ellos pudiera tener el cabildo eclesiástico de Durango. Evidentemente esta institución se quejó, alegando que según la Ley II,

103 Toda ella esta recogida en AGI, Guadalajara, 561. 
Título LXXI, Libro I, de la Recopilación de las Leyes de Indias, los diezmos no pertenecían a los obispados hasta que los obispos eran confirmados por el Papa; y no se debían entregar hasta que estos no ocupaban sus sedes; por tanto, era improcedente la retención que se había hecho, ya que en Nuevo México ni siquiera había obispo presentado, por lo que no se tenía derecho a tales diezmos. Ni siquiera se podían acoger a lo expuesto en las Cortes de Cádiz, donde, el 14 de junio de 1811, alegando que la dificultad de comunicación entre España y América no permitía los viajes de los prelados nombrados, que tomaban posesión en España, podían disfrutar de la mitad de las rentas, si estas pasaban de 35.000 pesos; de dos tercios cuando importaban de 25.000 a 35.000 pesos; y de tres cuartos cuando eran de 15.000 a 25.000. Por debajo de esas cantidades podían disfrutar del total. El problema en Nuevo México era que ni siquiera existía un obispo nombrado para tomar posesión. El Cabildo de Durango recordaba también a Bonavia que al seminario solo le correspondía el 3\% de la gruesa decimal; además que se debía tener en cuenta que los diezmos se cobraban con mucho retraso. Incluso se atrevía a sugerir que si no hubiese gastos en la construcción del seminario se deberían emplear en la instrucción de la juventud.

Lo cierto es que en la Península en el Consejo y Cámara de Indias, el 7 de septiembre de 1814, decían desconocer los motivos por los que las Cortes de Cádiz habían desgajado Nuevo México del obispado de Durango. De nuevo se iniciaban los trámites y el 27 de enero del año siguiente se enviaba una real cédula a Bonavia, que recibió el 29 de septiembre, en la que se le pedía la opinión de si convenía el nuevo obispado. La misma cédula se había enviado a otras autoridades civiles y eclesiásticas. El 19 de noviembre, el fiscal del Consejo llegaba a la conclusión de que el expediente no estaba suficientemente instruido y pedía que se enviasen nuevas cédulas al Comandante para que respondiese a algunas cuestiones.

Ahora el problema que le planteaban era que se desconocían los antecedentes que daban lugar a la erección de una nueva diócesis, pues lo único que se tenía era la propuesta del diputado Pino a las Cortes y el dictamen favorable que había dado la Comisión Ultramarina. Como consecuencia se expidió otra cédula el 27 de enero de 1815, por la que los ayuntamientos de Durango y Santa Fe debían dar razón de la necesidad del obispado, del territorio que debía comprender, del importe de los diezmos con los que se podía contar, y de otros aspectos que se considerasen oportunos. De nuevo contestaría el Comandante el 12 de agosto de 1816 expre- 
sando por enésima vez la necesidad del obispado y que este se debía corresponder con la demarcación militar y política, amén de que los diezmos que producía eran suficientes; añadiendo, además, que una diócesis no solo proporcionaría bienes espirituales, sino también temporales.

El mayor problema que se planteaba ahora para las autoridades neomexicanas era el de la catedral y residencia del obispo, para la que pensaba que podía servir de forma momentánea la parroquia de San Francisco, en Santa Fe, aunque no era fácil adaptarla para convertirla en catedral, ${ }^{104}$ ya que no dejaba de ser una iglesia que, aunque actuase como parroquia de españoles, no pasaba de tener un trazado misional y de ser una construcción muy simple de adobe y madera, como era tradicional en la arquitectura de Nuevo México. ${ }^{105}$

Bonavia enviaba además los informes que le habían entregado los ayuntamientos de Santa Fe y Durango, así como el cabildo eclesiástico de este último lugar. Todos ellos eran del parecer de que se erigiera la nueva diócesis. El Cabildo de Durango insistía en que los diezmos de Nuevo México eran de unos 10.000 pesos y que ello era suficiente para la subsistencia del prelado, pues el de Sonora se mantenía con poco más de la mitad de aquella cantidad; dicho cabildo manifestaba que además se podían añadir los proventos del curato de Santa $\mathrm{Fe}$ «y aun pensionarse los más pingües del nuevo obispado al tiempo de su provisión en la tercera parte de obvenciones y derechos libres para la fundación del seminario». Precisamente los diezmos de Nuevo México, en términos generales, fueron en aumento desde 1780 hasta la independencia. ${ }^{106}$

No les parecieron suficientes aquellas informaciones a las autoridades peninsulares y otra vez se mandó al comandante general que hiciese una estadística que reflejase la población, artes, industria, labranza, comercio y riquezas. En realidad parece que lo que importaba era dilatar el asunto sin provocar el descontento de la población.

En 1817 las cosas habían variado muy poco. En España se reconocía la necesidad del obispado, pero se dudaba de los medios para dotarlo. Amén de esto, ahora se reconocía expresamente una realidad que preocu-

104 Se enviaba un plano muy esquemático y no muy preciso de la iglesia parroquial de San Francisco de Santa Fe, que se conserva en el AGI, Mapas y planos, México 704. Fue publicado recientemente en el catálogo de la exposición organizada por González y Lázaro, 2011, 94-95.

105 AGI, Indiferente, 248, N. 109, «Méritos de Juan Bautista Ladrón del Niño de Guevara», 25 de mayo de 1819.

106 Frank, 1996, 755. 
paba a las autoridades españolas y que no se había mencionado tan claramente en todo este proceso, aunque hubiese estado latente. Se trataba de la situación emancipadora de Nueva España, en que a pesar de la aparente tranquilidad por aquellos años, existían serias dudas para considerar la revolución como controlada. Esta cuestión, además, debía relacionarse con el cobro de los diezmos, pues sería difícil hacerlo en una situación de conflicto. Se ponía como ejemplo el obispado de Guadalajara, que disponía de grandes ingresos por este concepto, pero que no podía disfrutarlos. En consecuencia el fiscal del Consejo era ya contrario a crear la nueva diócesis, al menos hasta que el país se hallase fuera de todo peligro.

Como mencionamos, probablemente para no provocar un descontento en la población en unos momentos tan delicados, no cesó la petición de informes, como el que se hizo el 18 de abril de 1818 al comandante general de las Provincias Internas Occidentales, que a la sazón ya lo era Alejo García Conde (1817-1821). Esto sucedía cuando los habitantes de Nuevo México estaban más dispuestos a conseguir sus propósitos y por ello, incluso, propondrían un prelado en la figura de Juan Bautista del Niño Ladrón de Guevara, secretario del obispo de Durango, del que informaba muy positivamente dicho prelado y del que se formó una relación de méritos. ${ }^{107}$ Aquel hombre había llegado a Durango en 1803 y se decía que era descendiente de la noble familia de los Guevara de Estella, cuyo marquesado se hallaba unido al condado de Oñate, de cuya casa era descendiente el conquistador de aquellos territorios, Juan de Oñate. El propuesto no era un desconocido para los neomexicanos, puesto que había sido encargado de hacer una visita al territorio por el obispo Castañiza, entre 18171820, desarrollando una gran labor. En esa visita había abordado los problemas de supersticiones, que abundaban en la provincia, algunas muy relacionadas con la muerte y las cofradías de terceros; ${ }^{108}$ igualmente denunció el mal estado de los templos, pues el de El Paso, que era el mejor considerado, lo describía el visitador como peor que una bodega. ${ }^{109} \mathrm{Al}$ mismo tiempo reconocía que se había encontrado con una situación del clero muy semejante a la que mencionaba Pino, pues había 23 franciscanos y cuatro clérigos.

107 AGI, Indiferente 248, N. 109. «Méritos de Juan Bautista Ladrón del Niño de Guevara», 25 de mayo de 1819 .

108 Existe una abundante bibliografía sobre este asunto, que puede verse en una autora que ha tratado el tema como Weigle, 2007 y su famosa obra de 1976.

109 Archives of the Archdiocese of Santa Fe, Accounts 52. 
Los neomexicanos seguían luchando por su diócesis, ya que veían en ella una forma de engrandecer la provincia, de fomentar las artes y la agricultura, aumentar el comercio; en fin, que se mantenía el espíritu de los ilustrados de contribuir por medio del desarrollo a la felicidad del pueblo. Como consecuencia, varias autoridades civiles y militares de la provincia firmaron un escrito apoyando la diócesis en una solicitud dirigida al ministro de Gracia y Justicia, el 5 de enero de 1818. Por lo demás, las consideraciones que se exponían seguían siendo las mismas: límites que coincidiesen con los castrenses y mantenimiento con los diezmos de la diócesis. Respecto a estos se aclaraba que, puestos en arrendamiento, producirían 11.000 pesos, pero que si se controlaran por administradores podrían suponer más de 12.000 pesos, de los que 5.000 serían para el obispo. Entre aquellos firmantes no aparecía el nombre de Pedro Baptista Pino, el gran promotor de la diócesis en las Cortes de Cádiz, que había regresado a Nuevo México, donde se había enriquecido y que sería elegido de nuevo diputado en las elecciones de 24 de septiembre de 1820, con ocho votos de los 14 electores. Sin embargo no regresaría a España, porque no se le abonaron las dietas y por las dificultades en las comunicaciones. ${ }^{110}$ Desconocemos que proposiciones traería entonces, pero sin duda estaría entre ellas la del nuevo obispado, que no llegaría a fundarse durante el poco tiempo que quedaba del periodo español, a pesar de que a Santa Fe se le había concedido el estatus de ciudad, en 1819. Tras la independencia, por decreto de 19 de julio de 1823, el Congreso mexicano mantenía lo aprobado en las Cortes gaditanas, incluso se instó al obispo de Durango para que, hasta que se crease un obispado en Nuevo México, nombrase un vicario foráneo; y para tal se nombró a Agustín Fernández de San Vicente, prebendado de Durango. ${ }^{11}$

Con la independencia se desarrollaría la presencia del clero secular, lo que no se había logrado durante todo el periodo español, a pesar de los esfuerzos, ni siquiera en las Cortes de Cádiz. Los golpes de gracia a los franciscanos serían los decretos de expulsión de México de los españoles, en 1827 y 1829 , y el decreto del Congreso para la secularización de las misiones, en 1834. Lo cierto es que los hijos de san Francisco fueron perdiendo presencia, no siempre compensada por los seculares; así, de los 23 frailes que había en el momento de la independencia, ya tan solo eran nue-

110 ACD, Serie Documentación electoral, 7, n. ${ }^{\circ} 18$.

111 Memoria de los ramos, 1826, 18-19. Memoria de los decretos, 1825, 159. 
ve en 1826, junto a cinco seculares. Los seráficos desaparecerían en 1848, cuando murió el último de ellos, fray Mariano de Jesús, coincidiendo con la firma del tratado de Guadalupe-Hidalgo, por el que Nuevo México pasaba a depender definitivamente de los Estados Unidos de Norteamérica.

La independencia había supuesto el triunfo definitivo del clero secular criollo de la diócesis de Durango frente a lo frailes, españoles en su mayoría, y que curiosamente no aparecen representados en toda esa información de la última década de dependencia española, probablemente porque ya habían asumido la imparable secularización.

Fue después de la anexión a los Estados Unidos cuando por fin se creó el obispado de Nuevo México por bula de Pío IX, el 29 de julio de 1853, convirtiéndose en 1875 en archidiócesis, siendo en ambos casos el primer beneficiario de la mitra el francés Jean Baptiste Lamy, con el que la influencia española y novohispana en la iglesia neomexicana quedó desterrada y fue suplida por una masiva presencia del clero francés.

Recibido el 29 de febrero de 2012 Aceptado el 25 de septiembre de 2012

\section{Bibliografía}

Abert, James W.: Abert s New Mexico Report 1846-'47, ed. de William Kelleher, Albuquerque, Horn \& Wallace, 1962.

Almada, Francisco R.: «El Norte: Chihuahua», en Piñera Ramírez, David (ed), Visión histórica de la frontera norte de México, II, De los aborígenes al septentrión novohispano, Mexicali, Universidad Autónoma de la Baja California, 1994.

Andrade, Vicente de P.: Noticias biográficas sobre los ilustrísimos prelados de Sonora, de Sinaloa y de Durango, México, Imprenta del Museo Nacional, 1899.

Beccari, Cammillo: Rerum Aethiopicarum Scriptores Occidentales inediti a seculo XVI ad XIX, Roma, C. de Luigi, 1903-1917.

Benavides, Alonso de: Memorial que fray Juan de Santander de la Orden de San Francisco, comisario general de Indias, presenta a la Majestad Católica del Rey don Felipe Cuarto nuestro señor hecho por el Padre..., Madrid, Imprenta Real, 1630.

Cárdenas, Gabriel de: Ensayo cronológico para historia general de la Florida, Madrid, Nicolás Rodríguez Franco, 1722. 
Chávez, Angélico: «El Vicario Don Santiago Roybal», El Palacio, 55-8, Santa Fe N.M., 1948, 231-252.

Chávez, Angélico: «Santa Fe Church and Convent Sites in the Seventeenth and Eighteenth Centuries», New Mexico Historical Review, 24-2, Albuquerque, 1949, 85-93.

Chávez, Angélico: Origins of New Mexico Families. A Genealogy of the Spanish Colonial Period, Santa Fe, Museum of New Mexico Press, 1992.

Colección de los decretos y órdenes de las Cortes de España que se reputan vigentes en la República de los Estados Unidos Mexicanos, México, Galván, 1829.

Cortes. Actas de las sesiones de la legislatura ordinaria de 1814, Madrid, Viuda e hijos de J. Antonio García, 1876.

Cutter, Charles R.: «La Real Audiencia del norte de la Nueva España. Historia de un proyecto frustrado», Memoria del X Congreso del Instituto Internacional de Historia del Derecho Indiano, I, México, UNAM, 1995, 277-292.

Cramaussel, Chantal: «Tierra Adentro y Tierra Afuera, el septentrión de la Nueva España», en Mazín Gómez, Oscar (ed.), México en el Mundo Hispánico, I, Zamora Mich., El Colegio de Michoacán, 2000, 69-82.

Diálogos patrióticos, México, María Fernández de Jáuregui, 1811.

Diario de sesiones de las Cortes Generales y Extraordinarias, Madrid, J.A. García, 1870.

Domínguez, Atanasio: The Missions of New Mexico, 1776. A Description by fray Atanasio Domínguez with other Contemporary Documents, ed. de Eleanor B. Adams y Angélico Chávez, Albuquerque, University of New Mexico Press, 1975.

Donís Ríos, Manuel Alberto: «Una aproximación a la historia territorial de la provincia de Mérida en el siglo XIX», Presente y Pasado 13-26, MéridaVenezuela, 2008, 213-248.

Flagler, Edgard K.: Defensores de la Madre Tierra. Relaciones interétnicas: los españoles y los indios de Nuevo México, Palma de Mallorca, Juan José de Olañeta, 1997.

Frank, Ross: «Economic Growth and the creation of the Vecino Homeland in New Mexico, 1780-1820», Revista de Indias, 56-208, Madrid, 1996, 743-782.

González Díaz, Falia y Lázaro Escosura, Pilar: The Threads of Memory, Santa Fe, New Mexico History Museum, 2011.

González de la Vara, Martín: «La visita eclesiástica de Francisco Atanasio Domínguez al Nuevo México (1776) y su relación», Estudios de Historia Novohispana, 10-10, México, 1991, 267-288.

Gutiérrez, Ramón A.: Cuando Jesús llegó, las madres del maíz se fueron. Matrimonio, sexualidad y poder en Nuevo México, 1500-1846, México, Fondo de Cultura Económica, 1993. 
Hacket, Charles W. (ed.): Historical Documents relating to New Mexico, Nueva Vizcaya and approaches thereto, to 1773, III, Washington, Carnegie Institution, 1937.

Hendricks, Rick: «The Church in El Paso del Norte in the Eighteenth Century», en Steele, Thomas J., S.J., Rhetts, Paul and Awalt, Barbe (eds.), Seeds of Struggle, Harvest of Faith: Papers of the Archdiocese of Santa Fe Catholic Cuarto Centennial Conference on the History of the Catholic Church in New Mexico, Albuquerque, LPD Press, 1998, 101-118.

Kessell, John I.: Kiva, Cross and Crown. The Pecos Indians and New Mexico, 1540-1840, Albuquerque, University of New Mexico Press, 1987.

Kessell, John I., Hendricks, Rick y Dodge, Meredith (eds.): To the Royal Crown Restored.The Journals of Don Diego Vargas, 1692-1694, Albuquerque, University of New Mexico, Press, 1995.

Lange, Frédérique: «La representación venezolana en las Cortes de Cádiz: José Domingo Rus», Boletín Americanista, 5, Barcelona, 1995, 221-247.

López, Eucario: Centenario de la Archidiócesis de Guadalajara. Antecedentes de su erección, Guadalajara, s/e, 1964.

López Cancelada, Juan: La intriga y la constancia. Opúsculo dedicado a la probidad de Cancelada, Cádiz, Imprenta Patriótica, 1818.

López Cancelada, Juan: El Telégrafo americano (10 de octubre de 1811 al 31 de marzo de 1812), León, Universidad de León, 2008.

Memoria de los decretos y órdenes del Soberano Congreso Mexicano desde su instalación en 24 de febrero de 1822 hasta 30 de octubre de 1823, en que cesó, México, Imprenta del Superior Gobierno, 1825.

Memoria de los ramos del Ministerio de Relaciones Interiores y Esteriores (sic) de la República, leída en las cámaras del soberano Congreso en los días 9 y 14 de enero del año 1826, México, Imprenta del Superior Gobierno, 1826.

Mota Padilla, Matías de la: Historia de la conquista de la provincia de la Nueva Galicia, México, Imprenta del Gobierno, 1870.

Navarro García, Luis: Las Provincias Internas en el siglo XIX, Sevilla, Escuela de Estudios Hispanoamericanos, 1965.

«Noticias de la Nueva España en 1805», Boletín de la Sociedad Mexicana de Geografía y Estadística, 2, México, 1850, 3-51.

Osorio Romero, Ignacio: Colegios y profesores jesuitas que enseñaron Latín en la Nueva España (1572-1767), México, UNAM, 1979.

Pacheco Rojas, José de la Cruz: El Colegio de Guadiana de los jesuitas 15961767, Durango, Universidad Juárez, 2004.

Palafox y Mendoza, Juan de: Ideas politicas, México, UNAM, 2006.

Pino, Pedro Baptista y López Cancelada, Juan: Exposición sucinta y sencilla de la provincia del Nuevo México y otros escritos, ed. de Jesús Paniagua Pérez, Valladolid, Junta de Castilla y León, 2007. 
Portillo Valadez, José Antonio: «El seminario de Monterrey. La educación católica en la diócesis de Monterrey», en Piñera Ramírez, David (coord.), La educación superior en el proceso histórico de México, III, Mexicali, Universidad Autónoma de Baja California, 2002.

Olmos Sánchez, Isabel: «Incidencia de la reforma de regulares en la estructura eclesiástica de Nueva España (1812-1820)», Estudios de Historia Social y Económica de América, 10, Alcalá de Henares, 1993, 207-215.

Ramírez, José Fernando: Noticias históricas y estadísticas de Durango (18491850), México, Ignacio Cumplido, 1851.

Rieu-Millan, Marie Laure: Los diputados americanos en las Cortes de Cádiz (igualdad o independencia), Madrid, CSIC, 1990.

Roca Roca, Eduardo, América en el ordenamiento jurídico de las Cortes de Cádiz, Bogotá, Universidad del Rosario, 1999.

Saravia, Atanasio G.: Obras III. Apuntes para la historia de la Nueva Vizcaya, México, UNAM, 1993.

Simons, Marc: Spanish Government in New Mexico, Albuquerque, University of New Mexico Press, 1990.

Simons, Marc: «In the Shadow of the Miter: New Mexico s Quest for Diocesan Status», en Steele, Thomas J., S.J., Rhetts, Paul and Awalt, Barbe (eds.), The History of the Catholic Church in New Mexico, Albuquerque, LPD Press, 1998, 207-218.

Santos Hernández, Ángel: Jesuitas y obispados. Los jesuitas obispos y misioneros y los obispos jesuitas de la extinción, Madrid, Universidad de Comillas, 2000.

Scholes, France V.: «Church and State in New Mexico, 1610-1650», New Mexico Historical Review, 11 y12, Albuquerque, 1936-1937, 11: 1-76, 145-178, 283 294, 297-347, 12: 78-101.

Steele, Thomas J., S.J., Rhetts, Paul and Awalt, Barbe (eds.): Seeds of struggle/harvest of faith: the papers of the Archdiocese of Santa Fe Catholic Cuarto Centennial Conference: the history of the Catholic Church in New Mexico, Albuquerque, LPD Press, 1998.

Tamarón y Romeral, Pedro: Demostración del vastísimo obispado de la Nueva Vizcaya-1765, Durango, Sinaloa, Sonora, Arizona, Nuevo México, Chihuahua y porciones de Texas, Coahuila y Zacatecas, México, Porrúa, 1937.

Tapia Méndez, Aureliano: Obispado del Nuevo Reino de León. Primer tiempo, Monterrey, AGENL, 1988.

Torre Villar, Ernesto de la: Instrucción reservada que dio el virrey don Miguel José de Azanza a su sucesor don Félix Berenguer de Marquina, México, Jus, 1960.

Torre Villar, Ernesto de la: «Erección de obispados en el siglo XVIII. El obispado de Valles», Estudios de Historia Novohispana, 3, México, 1970, 173-234. 
Treib, Marc: Sanctuaries of Spanish New Mexico, Berkeley, California University Press, 1993.

Trujillo, Manuel María: Exhortación Pastoral. Avisos importantes y reglamentos útiles, que para mejor observancia de la disciplina regular e ilustración de la Literatura en todas las provincias y colegios apostólicos de América y Filipinas, Madrid, Viuda de Ibarra, 1796.

Twitchell, Ralph Emerson: The Spanish Archives of New Mexico II, Santa Fe, Sunstone Press, 2008.

Valenzuela, Ramiro de: Memorial ajustado, que de orden del Consejo Supremo de Indias se ha hecho del pleyto, que siguió el ill. mo sor. don Benito Crespo, obispo que fue de Durango. Y lo continua el ill. mo. sor. don Martín de Elizacohea, su successor en dicho obispado. Con la religión de n.p.s. Francisco, de la regular observancia, y su procurador general de las Indias. Sobre visitar, y exercer los actos de la jurisdicción diocesana en la custodia del Nuevo México en la Nueva España, poner vicario foraneo, y otras cosas, Madrid, 1738.

Valenzuela, Ramiro de (ed.): Política Indiana, de Solórzano Pereira, Madrid, Imprenta Real de la Gazeta, 1776.

Vázquez Loya, Dizan: Las misiones franciscanas en Chihuahua. Pistas y referencias para su investigación, Chihuahua, Universidad Autónoma de Ciudad Juárez, 2004.

Weber, David J.: Bárbaros. Los españoles y sus salvajes en la era de la Ilustración, Barcelona, Crítica, 2007.

Weigle, Marta: Brothers of Blood. The Penitentes of the Southwest, Albuquerque, University of New Mexico Press, 1976

Weigle, Marta: A Penitente Bibliography, Santa Fe, Sunstone Press, 2007.

Will de Chaparro, Martina E.: «De cuerpo a cadáver: el tratamiento de los difuntos en Nuevo México en los siglos XVIII y XIX», Relaciones, 94, Zamora Mich., 2003, 61-90.

Wright, Robert E.: «How Many Are "A Few"? Catholic Clergy in Central and Northern New Mexico. 1780-1851», en Steele, Thomas J., S.J., Rhetts, Paul and Awalt, Barbe (eds.), Seeds of Struggle/Harvest of Faith. The papers of the Archidiocese of Santa Fe. Catholic Cuatro Centenal Conference. The History of the Catholic Church in New Mexico, Albuquerque, The Archidiocese of Santa Fe, 1998, 219-262.

Webb Hodge, Frederick, et al.: Fray Alonso de Benavides' revised Memorial of 1634, Albuquerque, University of New Mexico Press, 1945.

Zárate Toscano, Verónica: «El testamento político de los diputados americanos en 1814», Anuario de Estudios Americanos, XLV, Sevilla, 1988, 343-382. 